\title{
What are the social, psychological and physical health challenges facing adolescents in the UK?
}

Abstract

To say that adolescence is an important time of life is a colossal understatement. The ages of ten to nineteen are monopolised by biological, psychological and sociocultural changes, all of which impact health in the present and future. Adolescents have specific health needs that differ from children and adults ${ }^{1}$. Adolescence is a time to develop a self-identity, acquire skills and knowledge and begin to assume adult roles in society ${ }^{8}$. Behaviours and habits acquired during adolescence can have long-term impacts ${ }^{9}$. This essay will outline some key challenges facing adolescents in the United Kingdom (UK) today.

The current generation of adolescents are uniquely affected by contemporary factors such as social media and air pollution, the impacts of which have yet to be fully unravelled. As a result, interventions aimed at improving adolescent health will need to evolve to remain relevant.

Keywords

Adolescence, sociocultural change
Triya Chakravorty BSc

$4^{\text {th }}$ MBBS student, University of Oxford

Triya.chakravorty@queens.ox.ac.uk

Cite as: Chakravorty, T. What are the social, psychological and physician challenges facing adolescents in the UK? The Physician 2020 vol 6; issue 2 DOI: 10.38192/1.6.2.26

Article Information

Submitted 13 Sep 2020

Epub 16 Sep 2020

Published30 Sep 2020

Revised 22 Nov 2020

Open access Creative Commons

Licence CC-BY-ND-4.0 
Introduction

To say that adolescence is an important time of life is a colossal understatement. The ages of ten to nineteen are characterised by biological, psychological and sociocultural changes, all of which impact health in the present and future. Adolescents have specific health needs that differ from children and adults ${ }^{1}$. The notion that adolescence is a unique part of life is not limited to humans. In fact, many of the behaviours stereotypically associated with adolescence (for example, increased risk taking) are seen in other species too ${ }^{2}$.

Physically, adolescents go through several changes, such as the development of secondary sexual characteristics and growth to their adult height ${ }^{3}$. These changes do not occur in uniformly amongst all adolescents; they depend on factors such as ethnicity, gender and body mass index, as well as external factors such as nutrition and the social environment ${ }^{4-6}$. Brain maturation is not complete until around twenty-five, which suggests that experiences which occur during adolescence can significantly impact neural development ${ }^{7}$. There are many sociocultural changes that occur also. Adolescence is a time to develop a self-identity, acquire skills and knowledge and begin to prepare to assume adult roles in society ${ }^{8}$.

Behaviours and habits acquired during adolescence can have long-term impacts ${ }^{9}$. Smoking, alcohol use, obesity and physical inactivity are all examples of health-related behaviours that usually start in adolescence and contribute to the global epidemic of non-communicable diseases in adults ${ }^{10,11}$. These behaviours are influenced by socioeconomic and cultural factors and are major determinants of future health inequalities ${ }^{12}$. This essay will outline some key challenges facing adolescents in the United Kingdom (UK) today.

\section{Mental Health}

Mental health disorders are one of the largest contributors to the burden of disease in adolescence globally ${ }^{13}$. The World Health Organisation (WHO) estimate that $10-20 \%$ of all children and adolescents experience mental health problems ${ }^{14}$. It is estimated that half of all mental health disorders are established by fourteen years ${ }^{15,16}$. Furthermore, the prevalence of depression and anxiety in adolescence has increased significantly in the past twenty-five years, and in the UK, the rate of self-harm in girls aged 1316 has risen by $68 \%$ in the past decade ${ }^{17,18}$. The reasons for these increases are not fully known. However, depression and anxiety have several adverse consequences on development, such as lower academic performance, impaired social relationships, increased risk of substance abuse and suicide $^{18}$. Therefore, understanding the impact of mental health disorders on adolescent health is a priority.

\section{Social Determinants}

The WHO defines the social determinants of health as "the conditions in which people are born, grow, live, work and age" ${ }^{5}$. Education is one of the strongest social determinants of health ${ }^{19}$, and completing secondary school is associated with improved health outcomes ${ }^{9}$. This is particularly relevant in England, since changes in the education system have led to the extension of the age for compulsory participation in education or training to eighteen, making this a positive initiative for health reasons also ${ }^{20}$.

The impact of education is vast and exceeds beyond gaining qualifications. School is an important social environment which can influence peer connections, emotional wellbeing and health. A stronger engagement of adolescents and their families with school positively effects health outcomes directly ${ }^{9,21}$. In the UK, poor academic performance is a risk factor for adolescent smoking. Furthermore, adolescents tend to have friendship ties with people of the same smoking status and level of academic performance ${ }^{22}$. Therefore, anti-smoking interventions that target poor academic performance specifically may be beneficial to decrease smoking related heath inequalities in the long-term.

\section{Socioeconomic Status}

Living arrangements and employment status are important determinants of health. Whilst youth homelessness in the UK is difficult to quantify, several reports indicate a recent increase ${ }^{23}$. Homelessness during adolescence has several detrimental effects, such as an increased risk of infectious diseases, alcohol use and mental health disorders $^{20}$, and being at risk of child sexual exploitation and abuse. Furthermore, many homeless adolescents may go undetected by official counts $^{20}$. Adolescents who report sleeping on sofas of friends or on public transport are termed "hidden 
homeless ${ }^{\prime 20}$. This is a serious issue, as they may not receive the support they require.

Overall, those who are long-term unemployed have a lower life expectancy and worse health ${ }^{24}$. However, there is limited research into the impact of unemployment on adolescents specifically ${ }^{20}$. The recent shift in working patterns in the UK has seen more businesses using zero-hour contracts ${ }^{20}$. This may be particularly relevant to adolescent health, as adolescents on zero-hour contracts are more at risk of health problems compared to their peers ${ }^{25}$.

\section{Relationships}

Relationships with family, teachers and peers can affect adolescents mentally and physically. It is of no surprise that family structure plays an important role in human development, and can impact health in the long-term ${ }^{20}$. An observational study conducted in the United States of America showed that adolescents from two-parent households have higher self-rated health scores at age thirteen and in adulthood ${ }^{26}$. Parental behaviours also impact health. Adolescents whose parents smoke, drink or engage in violence are more likely to engage in these behaviours themselves ${ }^{9}$. This suggests that public health interventions that target both parents and adolescents may be useful in reducing these behaviours.

The formation of peer relationships is one of the key developmental changes of adolescence. This is important, since peers can have both positive and negative influences on health ${ }^{9}$. Peer relationships allow adolescents to buffer the effects of life stressors, however, peer rejection can cause considerable distress ${ }^{9,27}$. There is also significant evidence showing the role of peer influence in the development of antisocial behaviour, substance misuse and participating in criminal activity ${ }^{9,20}$.

One challenge facing adolescents regarding peer dynamics is bullying. In the UK, victims of bullying are more likely to be absent from school, have lower educational qualifications and increased mental health problems ${ }^{28}$. Although the UK government requires state-funded schools to include antibullying measures in their policies ${ }^{29}$, the rapid development of technology means that cyberbullying is a rising concern; the impacts of which are less documented.

Technology
What it means to be an adolescent today is vastly different compared to even the previous generation. This is partially due to technological innovations which have allowed for increased global connectivity, internet access and social media use ${ }^{7}$. Social media gives adolescents a platform with which to actively engage with world affairs and each other. However, its use can also negatively influence health. For example, several studies show a significant link between adolescent social media use and depression ${ }^{18}$. The reasons for this have not been completely elucidated, but the impact is likely multifactorial, involving factors such as impaired sleep, sedentary habits and addictive behaviour ${ }^{18}$.

Nevertheless, social media is an intensely powerful platform that can be used to promote the health of adolescents $^{30}$. For example, South African multimedia "edutainment" programme Soul City helped to change stereotypes about Acquired Immunodeficiency Syndrome and domestic violence, and has contributed to the empowerment of local communities ${ }^{31}$. Adolescents should be included in the development of future interventions using social media so as to accurately reflect their needs.

Internet addiction is an increasingly prevalent concern. Problematic internet use (PIU), defined as a psychological dependence and lack of control over the time spent online, is an important area of research, as it can impact emotional well-being, relationships and everyday functioning of adolescents $^{32}$. The symptoms of PIU are similar to those of substance-related addictions, including unpredictable behaviour and mood. Addictive behaviours that are developed in adolescence are likely to continue into adulthood, making this a particularly important issue ${ }^{33}$.

Excessive use of technology can also impact physical health via sleep disturbance. Sleep disturbance is associated with poor academic performance, increased risk of mood disorders and obesity ${ }^{34}$. As a result, the American Academy of Paediatrics recommend that young people should limit their screen time to avoid sleep disruption ${ }^{35}$. Furthermore, the use of behavioural modification strategies to improve sleep may have several benefits for adolescents.

Environmental Factors 
Air pollution is a worldwide environmental health issue, with particular concerns in large cities, where the air quality is relatively worse ${ }^{36}$. It is well known that air pollution is a strong risk factor for poor cardiovascular and respiratory health ${ }^{37}$. However, there is increasing evidence to suggest that air pollution is associated with mental health problems in adolescents as well ${ }^{38}$. The pathophysiology may involve the effect of inflammatory stimuli such as inhaled pollutants on the brain ${ }^{39}$.

Roberts et $\mathrm{al}^{38}$ investigated the associations between air pollution exposure during childhood with concurrent and later mental health problems in a cohort from London. They found that pollution concentration levels at age twelve were associated with an increased risk of depression at eighteen. Although further investigation is required to understand the mechanism of this association, this finding adds to the growing list of reasons why tackling pollution should be a top priority for the UK government.

\section{Conclusion}

The range of factors that affect adolescent health are vast. How adolescents develop is rapidly changing, and the link between health outcomes and social determinants is increasingly complex. The current generation of adolescents are uniquely affected by contemporary factors such as social media and air pollution, the impacts of which have yet to be fully unravelled. As a result, interventions aimed at improving adolescent health will need to evolve to remain relevant.

\section{References:}

1 World Health Organisation Sixty-fourth World Health Assembly. Resolution WHA 64.28: Youth and health risks.,

<http://apps.who.int/gb/ebwha/pdf_files/WHA64/A64_R2 8-en.pdf> (2011).

2 Spear, L. P. The behavioral neuroscience of adolescence., (Norton, 2010).

3 Susman, E. J. Modeling developmental complexity in adolescence: Hormones and behavior in context. Journal of Research on Adolescence 7, 283-306, doi:10.1207/s15327795jra0703_3 (1997).

$4 \quad$ Wang, Y. Is obesity associated with early sexual maturation? A comparison of the association in American boys versus girls. Pediatrics 110, 903-910, doi:10.1542/peds.110.5.903 (2002).

5 World Health Organisation - Health For The World's Adolescents - A second chance in the second decade, $<$ http://apps.who.int/adolescent/second-decade/> (2014).

6 Perry, C. L. in Promoting Health: Intervention Strategies from Social and Behavioral Research. Institute of
Medicine (US) Committee on Capitalizing on Social Science and Behavioral Research to Improve the Public's Health (eds B.D. Smedley \& S.L. Syme) (National Academies Press (US), 2000).

7 Blum, R. W., Bastos, F. I., Kabiru, C. W. \& Le, L. C. Adolescent health in the 21st century. Lancet 379, 15671568, doi:10.1016/S0140-6736(12)60407-3 (2012).

8 National Research Council and Institute of Medicine. Growing Up Global: The Changing Transitions to Adulthood in Developing Countries. . (The National Academies Press, 2005).

9 Viner, R. M. et al. Adolescence and the social determinants of health. Lancet 379, 1641-1652, doi:10.1016/S0140-6736(12)60149-4 (2012).

10 Beaglehole, R. et al. Priority actions for the noncommunicable disease crisis. Lancet 377, 1438-1447, doi:10.1016/S0140-6736(11)60393-0 (2011).

11 Sawyer, S. M. et al. Adolescence: a foundation for future health. Lancet 379, 1630-1640, doi:10.1016/S01406736(12)60072-5 (2012).

12 Mackenbach, J. P. et al. Socioeconomic inequalities in health in 22 European countries. N Engl J Med 358, 24682481, doi:10.1056/NEJMsa0707519 (2008).

13 Gore, F. M. et al. Global burden of disease in young people aged 10-24 years: a systematic analysis. Lancet 377 , 2093-2102, doi:10.1016/S0140-6736(11)60512-6 (2011).

14 WHO. Maternal, newborn, child and adolescent health.

<https://www.who.int/maternal_child_adolescent/topics/a dolescence/mental_health/en/> (2017).

15 Kessler, R. C. et al. Age of onset of mental disorders: a review of recent literature. Curr Opin Psychiatry 20, 359-364, doi:10.1097/YCO.0b013e32816ebc8c (2007).

16 Kim-Cohen, J. et al. Prior juvenile diagnoses in adults with mental disorder: developmental follow-back of a prospective-longitudinal cohort. Arch Gen Psychiatry 60, 709-717, doi:10.1001/archpsyc.60.7.709 (2003).

17 Morgan, C. et al. Incidence, clinical management, and mortality risk following self harm among children and adolescents: cohort study in primary care. BMJ 359, j4351, doi:10.1136/bmj.j4351 (2017).

18 Keles, B., McCrae, N. \& Grealish, A. A systematic review: the influence of social media on depression, anxiety and psychological distress in adolescents. International Journal of Adolescence and Youth 25, 79-93, doi:10.1080/02673843.2019.1590851 (2020).

19 Feinstein, L. et al. What are the effects of education on health? , <http://www1.oecd.org/education/innovationeducation/37425753.pdf> (2006).

20 Shah, R. et al. The social determinants of young people's health. Identifying the key issues and assessing how young people are doing in the 2010s, <https://www.health.org.uk/publications/the-socialdeterminants-of-young-people\%E2\%80\%99s-health> (2018).

21 Flay, B. R. et al. Effects of 2 prevention programs on high-risk behaviors among African American youth: a randomized trial. Arch Pediatr Adolesc Med 158, 377-384, doi:10.1001/archpedi.158.4.377 (2004).

22 Robert, P.-O. et al. Academic performance and adolescent smoking in 6 European cities: the role of friendship ties. International Journal of Adolescence and 
International Journal of Health

Youth 24, 125-135, doi:10.1080/02673843.2018.1475288 (2019).

23 Young and homeless research - Young \& Homeless report 2018, <https://www.homeless.org.uk/facts/ourresearch/young-and-homeless-research> (2018).

24 Bartley, M. Health Inequality: An Introduction to Concepts, Theories and Methods, 2nd Edition. (2016).

25 UCL. Being on a zero-hours contract is bad for your health. UCL News

, <https://www.ucl.ac.uk/news/2017/jul/being-zero-hourscontract-bad-your-health> (2017).

26 Sokol, R., Ennett, S., Gottfredson, N. \& Halpern, C. Variability in self-rated health trajectories from adolescence to young adulthood by demographic factors. Prev Med 105, 73-76, doi:10.1016/j.ypmed.2017.08.015 (2017).

27 Acquah, E. O., Topalli, P.-Z., Wilson, M. L., Junttila, N. \& Niemi, P. M. Adolescent loneliness and social anxiety as predictors of bullying victimisation. International Journal of Adolescence and Youth 21, 320-331, doi:10.1080/02673843.2015.1083449 (2016).

28 Wolke, D. \& Lereya, S. T. Long-term effects of bullying. Arch Dis Child 100, 879-885, doi:10.1136/archdischild-2014-306667 (2015).

29 Education Policy Institiute - Bullying: A review of the evidence, <https://epi.org.uk/publications-andresearch/bullying-a-review-of-the-evidence/> (2018).

30 Lau, P. W., Lau, E. Y., Wong del, P. \& Ransdell, L. A systematic review of information and communication technology-based interventions for promoting physical activity behavior change in children and adolescents. J Med Internet Res 13, e48, doi:10.2196/jmir.1533 (2011).

31 Scheepers, E. et al. Evaluating health communication - a holistic overview of the impact of Soul City IV. Health Promotion Journal of Australia 15, 121-133, doi:10.1071/he04121 (2004).

32 Anderson, E. L., Steen, E. \& Stavropoulos, V. Internet use and Problematic Internet Use: a systematic review of longitudinal research trends in adolescence and emergent adulthood. International Journal of Adolescence and Youth 22, 430-454, doi:10.1080/02673843.2016.1227716 (2017).

33 Coffey, C., Carlin, J. B., Lynskey, M., Li, N. \& Patton, G. C. Adolescent precursors of cannabis dependence: findings from the Victorian Adolescent Health Cohort Study. Br J Psychiatry 182, 330-336, doi:10.1192/bjp.182.4.330 (2003).

34 Kubiszewski, V., Fontaine, R., Rusch, E. \& Hazouard, E. Association between electronic media use and sleep habits: an eight-day follow-up study. International Journal of Adolescence and Youth 19, 395-407, doi:10.1080/02673843.2012.751039 (2014).

35 Children, Adolescents, and Television. Pediatrics 107, 423-426, doi:10.1542/peds.107.2.423 (2001).

36 Review of evidence on health aspects of air pollution - REVIHAAP Project: Technical Report [Internet]. (WHO Regional Office for Europe, Copenhagen, 2013).

37 Kelly, F. J. \& Fussell, J. C. Air pollution and public health: emerging hazards and improved understanding of risk. Environmental Geochemistry and Health 37, 631-649, doi:10.1007/s10653-015-9720-1 (2015).

38 Roberts, S. et al. Exploration of NO2 and PM2.5 air pollution and mental health problems using high-resolution data in London-based children from a UK longitudinal cohort study. Psychiatry Res 272, 8-17, doi:10.1016/j.psychres.2018.12.050 (2019).

39 Danese, A. \& Baldwin, J. R. Hidden Wounds? Inflammatory Links Between Childhood Trauma and Psychopathology. Annu Rev Psychol 68, 517-544, doi:10.1146/annurev-psych-010416-044208 (2017). 